\title{
O CONTROLE DE POLÍTICAS PÚBLICAS PELO JUDICIÁRIO COM FUNDAMENTO NO PRINCÍPIO DA PROIBIÇÃO DE PROTEÇÃO INSUFICIENTE
}

\author{
Tamiris Alessandra Gervasoni ${ }^{1}$ \\ Mônia Clarissa Hennig Leal ${ }^{2}$
}

\begin{abstract}
RESUMO
O presente trabalho, com o auxílio do método dedutivo e do procedimento histórico-crítico, efetua uma abordagem histórica e conceitual do princípio da proibição de proteção insuficiente, diante da dupla face do princípio da proporcionalidade, partindo-se da noção de dever de proteção do Estado em relação aos direitos fundamentais. Analisando-se a proteção destes direitos prestacionais, pode-se dizer que são protegidos e concretizados pelo Estado, principalmente, por meio de políticas públicas. Contudo, em algumas situações, estas políticas públicas podem ser insuficientes e/ou ineficazes em sua proteção e promoção, surgindo neste momento a atuação do Poder Judiciário, através do controle jurisdicional de políticas públicas, como última salvaguarda. Neste aspecto, a dupla face do princípio da proporcionalidade assume relevo, essencialmente na perspectiva de proibição de proteção insuficiente, pois, diante desta situação, poderia o Poder Judiciário intervir, buscando estabelecer uma proteção suficiente. Assim, traçando um paralelo entre pesquisa jurisprudencial no Supremo Tribunal Federal com a doutrina especializada, será avaliado como a jurisdição constitucional brasileira tem utilizado esse princípio neste contexto.
\end{abstract}

Palavras-chave: Proteção insuficiente. Dever de proteção. Direitos fundamentais. Políticas públicas. Controle jurisdicional. Jurisdição constitucional.

\begin{abstract}
The present work, with the help of deductive and historical-critical procedure, performs a historical and conceptual approach of the principle of prohibition of insufficient protection, considering the double face of the principle of proportionality, starting from the State duty of protecting fundamental rights. By analyzing the provision of fundamental rights, it is possible to state that these rights are protected and upheld by the State, mainly through public policies. However, in some situations, these policies may be insufficient and/or ineffective, context in which the role of the judiciary in controlling public policies arises. In this aspect, the double face of the principle of proportionality gains relevancy, primarily from the perspective of the prohibition of insufficient protection, because, in these cases, the Judiciary could intervene, seeking to establish a sufficient protection. So, the main purpose of this paper is trace a parallel between jurisprudence researches in the Supreme Court with the specialized doctrine, aiming to analyze how the brazillian constitutional jurisdiction operates this principle in this context.
\end{abstract}

Keywords: Insufficient protection. Duty of protection. Fundamental Rights. Public policies. Jurisdictional control. Constitucional jurisdiction.

\footnotetext{
${ }^{1}$ Graduanda em Direito pela Universidade de Santa Cruz do Sul - UNISC. <tamirisgervasoni@gmail.com>

${ }^{2}$ Professora do Programa de Pós-Graduação em Direito - Mestrado e Doutorado da Universidade de Santa Cruz do Sul - UNISC. <moniah@unisc.br>
} 


\section{INTRODUÇÃO}

A proibição de proteção insuficiente decorre da dupla face do princípio da proporcionalidade, constituída em proibição de excesso (Übermassverbot) e em proibição de proteção insuficiente (Untermassverbot). Tal perspectiva surgiu através da jurisprudência alemã, com o advento da teoria do dever de proteção (Schutzpflicht), pois, diante desta, a atuação estatal, essencialmente na proteção dos direitos fundamentais, deveria observar certos níveis de proteção, de modo que não ultrapasse referidos parâmetros de excesso e insuficiência.

Neste sentido, analisando-se a proteção dos direitos fundamentais prestacionais, podese dizer que estes são protegidos e concretizados, principalmente, por meio de políticas públicas. Contudo, em algumas situações, estas políticas públicas podem ser insuficientes e/ou ineficazes na proteção e promoção dos direitos prestacionais, surgindo, neste momento, a possibilidade de atuação do Poder Judiciário, através do controle jurisdicional de políticas públicas, como última salvaguarda. Neste aspecto, a dupla face do princípio da proporcionalidade assume relevo, pois, diante de uma proteção insuficiente de determinado direito prestacional, poderia o Poder Judiciário intervir, buscando estabelecer uma proteção suficiente. Isto se dá, pois a insuficiência significa(ria) desproporcionalidade, podendo o Judiciário adotar a proporcionalidade como critério para exercer controle da política pública.

O presente estudo analisa, através de pesquisa jurisprudencial, os seis casos encontrados no Supremo Tribunal Federal por meio das palavras-chaves de busca Untermassvebot, "princípio de proibição da proteção insuficiente" e "proibição de proteção deficiente". Seguido do delineamento, traçou-se um paralelo com a doutrina especializada, a fim de avaliar, criticamente, como tem se portado a jurisdição constitucional em relação ao princípio da proibição de proteção insuficiente e como tem se dado - ou não - a sua utilização enquanto critério/fundamento para o controle jurisdicional de políticas públicas.

\section{MATERIAIS E MÉTODOS}

O estudo foi realizado com o auxílio do método dedutivo e do procedimento históricocrítico. Segundo a lógica da acepção clássica, a pesquisa parte da análise de elementos fundamentais, como o estudo e a análise da teoria do dever de proteção (Schutzpflicht), e da dupla face do princípio da proporcionalidade, para, em seguida particularizar a abordagem. 
Isto se dá através da observação da adequação dos aspectos estudados ao ordenamento constitucional brasileiro diante do controle jurisdicional de políticas públicas.

O método de procedimento utilizado foi o histórico, pois são analisados os aspectos históricos que contribuíram para a consolidação do tema abordado, bem como sua evolução e seus reflexos na sociedade atual. Quanto à técnica de pesquisa, utilizou-se a documentação indireta, através da pesquisa bibliográfica, como a consulta em livros, periódicos e jurisprudências, estas notadamente do Supremo Tribunal Federal, o que permitiu o estudo nos termos propostos.

Quanto à pesquisa jurisprudencial, as chaves de pesquisa utilizadas foram: Untermassverbot, princípio da proibição da proteção insuficiente e proibição da proteção suficiente. Foram considerados os diferentes termos, pois tais são utilizados como sinônimos pela doutrina especializada.

\section{FUNDAMENTAÇÃO TEÓRICA}

Partindo-se da premissa de dever de proteção do Estado em relação aos direitos fundamentais, associada à dimensão objetiva a eles atribuída pelo Tribunal Constitucional alemão por ocasião do célebre caso Lüth (1958), reforçada pelo mesmo Tribunal ao tratar sobre a descriminalização do aborto em duas situações, a primeira na BVerfGE 39 (1975) e a segunda na BVerfGE 88 (1993), o Estado estaria vinculado a observar determinados níveis de proteção aos direitos fundamentais. Assim, é reconhecido de modo expresso a teoria do dever de proteção (Schutzpflicht), em que ao Estado é atribuída a função de proteção e de defesa dos direitos fundamentais,

Em face da dimensão objetiva e do dever de proteção aos direitos fundamentais, (Schutzpflicht) o Estado não pode ser mais observado (apenas) como agressor destes direitos, mas ao revés, agora se transformou no como principal defensor e protetor, sendo também seu guardião. O Estado, ao zelar pelos direitos fundamentais, não pode considerar o dever de proteção como se fosse uma consequência natural e direta dos direitos fundamentais, mas, ao contrário, deve analisar que ela se constitui na outra face de tais direitos, sendo que, na Alemanha, é considerada como "a contraparte da função negativa dos direitos fundamentais" (STRECK, 2008) .

Assim, sua atuação não poderia ser excessiva, como, por exemplo, interferindo demasiadamente em determinado direito fundamental, nem insuficiente, de modo a deixar tal 
direito desprotegido. Neste sentido, portanto, apresenta-se a dupla face do princípio da proporcionalidade, constituída em proibição de excesso (Übermassverbot) e em proibição de proteção insuficiente (Untermassverbot), diante da teoria do dever de proteção (Schutzpflicht), especificamente quanto à atuação do judiciário ao interferir nas políticas públicas que estejam inobservando tal dever, apresentando-se de forma insuficiente e/ou ineficaz na concretização e proteção dos direitos fundamentais.

Exposta a origem e a evolução da teoria do dever de proteção (Schutzpflicht), observa-se que, de fato, esta preceitua uma obrigação de agir do Estado especificamente quanto aos direitos fundamentais. Entretanto, até o presente momento, não se conseguiu fixar de que forma esta atuação deveria ocorrer. A despeito disso, a jurisprudência alemã, na segunda decisão proferida sobre o aborto (BverfGE 88, 203), determinou que seria imprescindível que, em tal atuação, fosse observado o princípio da proporcionalidade, essencialmente os seus parâmetros extremos de excesso e insuficiência, sendo que a Constituição apenas determinaria a proteção como uma meta a ser alcançada, mas não o caminho a ser trilhado para se chegar nela. O Bundesverfassungsgericht assim se pronunciou:

\begin{abstract}
a Constituição fixa a proteção como meta, não detalhando, porém, sua configuração. No entanto, o legislador deve observar a proibição de insuficiência [...] ele está sujeito ao controle jurisdicional constitucional (pelo TCF). Considerando-se bens jurídicos contrapostos, necessária se faz uma proteção adequada. Decisivo é que a proteção seja eficiente como tal. As medidas tomadas pelo legislador devem ser suficientes para uma proteção adequada e eficiente e, além disso, basear-se em cuidadosas averiguações de fatos e avaliações racionalmente sustentáveis. A medida de proteção ordenada constitucionalmente segundo o supra verificado independe do tempo de gestação. A Grundgesetz não contém escalonamentos do direito à vida e de sua proteção em face da vida intra-uterina, a serem fixados de acordo com determinados prazos e seguindo o processo de desenvolvimento da gravidez. Por isso, o ordenamento jurídico deve garantir esta medida de proteção também na fase inicial de uma gravidez (MARTINS, 2005, p. 280).
\end{abstract}

Sendo a proteção suficiente dos direitos uma meta a ser alcançada, propõe-se no presente estudo que um dos possíveis caminhos que estariam aptos a encontrá-la seria a aplicação da proporcionalidade. Estaria, assim, em conformidade com o entendimento do Tribunal Constitucional Federal da Alemanha ao afirmar que o princípio da proporcionalidade, podendo ser observado também quanto à face de proibição de insuficiência, vincularia o Estado a determinados níveis de proteção aos direitos fundamentais, de forma que tais correspondessem à proteção suficiente dos direitos fundamentais e, assim, 
o Estado deve adotar medidas normativas e fáticas suficientes para cumprir seu dever de tutela, que levem - considerando os bens conflitantes - ao alcance de uma proteção adequada e, como tal, efetiva (proibição de insuficiência). Para tanto, é necessário um projeto de proteção que combine elementos de proteção preventiva e repressiva (MARTINS, 2005, p. 276).

Portanto, na busca de uma proteção suficiente, inicialmente poderia analisar-se o princípio da proporcionalidade no que concerne à sua dupla face, como leciona principalmente a doutrina alemã, tendo-se, primeiro, aquela que trata da proibição do excesso. Esta exerceria a função de parâmetro de avaliação da constitucionalidade das intervenções praticadas nos direitos fundamentais, não podendo ocorrer de modo excessivo, havendo, de certa forma, proibição de intervenção. Já quanto à outra face, a proibição de proteção insuficiente, pode ser compreendida, de certa forma, como imperativo de tutela, a qual deve assegurar um mínimo de proteção que esteja apto a manter um padrão constitucionalmente estabelecido:

o preceito da proporcionalidade segue logicamente do caráter principiológico dos direitos fundamentais e á aplicável tanto para obrigação de omissão estatal como também para obrigações de ações positivas. [...] Em época recente, surgiu, na Alemanha, o conceito da proibição da não-suficiência (Untermassverbot). Trata-se de conceito equivalente à proibição de excesso e deixa-se deduzir logicamente do caráter principiológico das obrigações de ação estatais. A proibição de nãosuficiência exige que o legislador (e também o administrador), se está obrigado a uma ação, não deixe de alcançar limites mínimos. O Estado, portanto, é limitado de um lado, por meio dos limites superiores da proibição de excesso, e de outro, por meio de limites inferiores da proibição da não-suficiência. (LEIVAS, 2006, p. 76).

Conforme já mencionado anteriormente, é eminente a existência de um dever de proteção do Estado e, portanto, para realizar tal dever, é necessário, inicialmente, que sua atuação seja pautada e estabelecida entre os parâmetros da dupla face da proporcionalidade, ou seja, que não se dê nem de forma insuficiente e nem de forma excessiva. Ocorre que, mesmo após a observação de tais parâmetros, é possível que ocorra desproporcionalidade no processo de concretização de algum direito fundamental e tal será constatado através do princípio da proporcionalidade. Conforme a lição de Carbonel, o princípio da proporcionalidade seria o limite dos limites dos direitos fundamentais:

de hecho, el principio de proporcionalidad constituye hoy en día quizá el más conocido y el más recurrente "límite de los límites" a los derechos fundamentales y en esa medida supone una barrera frente a intromisiones indebidas en el ámbito de los propios derechos (2008, p. 11).

Já no caso de proibição de proteção insuficiente ocorrerá uma atuação (ou, dependendo do caso, até mesmo omissão) aquém do mínimo firmado pela Constituição, ainda 
que esteja previsto meramente como meta ou objetivo a ser alcançado. Tal entendimento, no Brasil, já foi citado pelo Supremo Tribunal Federa:

\begin{abstract}
é tarefa do legislador determinar, detalhadamente, o tipo e a extensão da proteção. A Constituição fixa a proteção como meta, não detalhando, porém, sua configuração. No entanto, o legislador deve observar a proibição de insuficiência [...]. Considerando-se bens jurídicos contrapostos, necessária se faz uma proteção adequada. Decisivo é que a proteção seja eficiente como tal. (BRASIL, 2012, p. 18).
\end{abstract}

Desta forma, como se observa no trecho citado acima, extraído de decisão de relatoria do Ministro Gilmar Mendes, a realização de uma proteção adequada dos direitos fundamentais, observando-se como corolário a proibição da proteção insuficiente (Untermassverbot), não é faculdade daquele que atua em nome do poder público, assim como optar em efetivar tal proteção ou não, seja qual for dos três poderes. O que poderia ser passível de deliberação concerne à forma e à extensão de tal proteção, visto que a Constituição não delineia como efetuá-las, apenas confirma a obrigação de sua observação e eficiência.

O Estado, portanto, diante da concretização dos direitos fundamentais, ou até mesmo da sua busca, deve pautar sua atuação conforme os ditames do princípio da proporcionalidade para que tal não se dê de modo insuficiente ou excessivo, pois em sua atuação pode(rá) ocorrer desproporcionalidade. Desta forma, cita-se Sarlet et al.:

\begin{abstract}
[...] para a efetivação de seus deveres de proteção, corre o Estado - por meio de seus órgãos ou agentes - o risco de afetar de modo desproporcional outro(s) direito(s) fundamental (is), inclusive o(s) direito(s) de quem esteja acusado de violar direitos fundamentais de terceiros. Esta hipótese corresponde às aplicações correntes do princípio da proporcionalidade como critério de constitucionalidade das medidas restritivas de direitos fundamentais - atuantes, nesta perspectiva, como direitos de defesa. O princípio da proporcionalidade atua aqui, no plano da proibição de excesso como um dos principais limites às limitações dos direitos fundamentais. Por outro lado, poderá o Estado frustrar seus deveres de proteção atuando de modo insuficiente, isto é, ficando aquém dos níveis de proteção constitucionalmente exigidos ou mesmo deixando de atuar - hipótese, por sua vez, vinculada (ao menos em boa parte) à problemática das omissões inconstitucionais (2012, p. 338).
\end{abstract}

Assim, uma das possibilidades de verificar a desproporcionalidade da atuação do Estado no que tange aos direitos fundamentais, sua concretização e proteção, é a observação dos parâmetros de máximo e mínimo sob os quais deve manter-se tal atuação. Esta não pode exacerbar os limites de intervenção dos direitos fundamentais, não podendo ser excessiva, atingindo aquilo que não deveria atingir, pois, assim, está-se diante de um excesso, ultrapassando o parâmetro delimitador da face da proibição de excesso. 
A idéia de (Übermassverbot) sugere a existência de uma escala de intensidades de possibilidade de intervenção por parte do Estado. Haveria, pois, um certo limite de intensidade, o qual não poderia ser ultrapassado, sob pena de ferir frontalmente a Constituição (STRECK, 2008, p. 81).

De outro lado, tem-se que a atuação deve alcançar objetivos mínimos, que estejam aptos a proteger e garantir os direitos fundamentais de forma adequada, tal atuação não pode estabelecer-se aquém dos preceitos constitucionais pré-estabelecidos, visto que, de tal forma, não terá sido observado o parâmetro de atuação mínima, sendo violada a face de proibição de proteção insuficiente:

\begin{abstract}
los criterios para determinar la prohibición de defecto de protección son frecuentemente los contrarios a los utilizados en el principio de proporcionalidad en un sentido amplio, ya que como medida de control es necesaria su aplicación bajo la objetivización de los bienes jurídicos contrapuestos para determinar si se ha articulado una protección efectiva, suficiente y racional (CARA, 2010, p. 54).
\end{abstract}

Exemplo que poderia ilustrar a concretização de direito fundamental através do princípio da proporcionalidade é apresentado por Bolesina e Leal (2013) na questão do ensino fundamental no Brasil. Para atender ao direito à educação fundamental conforme padrões constitucionais previamente estabelecidos, ou seja, assegurar o direito fundamental de modo a ser protegido suficientemente, seria necessário assegurar aos alunos um ensino de qualidade (observando as diretrizes constitucionais de educação, como, por exemplo, as dispostas no artigo 205 e seguintes). Deveriam, também, ser observadas questões estruturais e físicas - como, por exemplo, materiais aos alunos, entre outras circunstâncias -, e que os padrões estabelecidos não carecem seguir modelos suíços. Porém, não podem demonstrar-se ineptos quanto ao objetivo de garantir um ensino de qualidade:

[...] a educação fundamental no Brasil: a escola não deve ser de padrões suíços, porém, tampouco pode ser defasada em recursos humanos (sem ou sem número suficiente de professores e funcionários) e materiais (sem ou sem número suficiente de mesas, cadeiras, telhado, condições de higiene) (BOLESINA; LEAL, 2013, p. 76).

Diante do exemplo apresentado, é possível, portanto, que determinada política pública adotada para concretizar e proteger específico direito fundamental possa ser insuficiente e/ou ineficaz e, desta forma, ao inobservar o parâmetro de proibição de proteção suficiente, estar-se-ia também transgredido o dever proteção necessário e obrigatório a ser prestado àquele direito fundamental: 
[...] a doutrina brasileira (e, em alguns casos, a própria jurisprudência), em que pese não ser pequena a discussão a respeito, em geral já aceita a ideia de que o princípio da proporcionalidade possui como que em um dupla face, atuando simultaneamente como critério para o controle da legitimidade constitucional de medidas restritivas do âmbito de proteção de direito fundamentais, bem como para o controle da omissão ou atuação insuficiente do Estado no cumprimento dos seus deveres de proteção. Em suma, desproporção [...] caracterizam violações ao princípio em apreço e, portanto, anitjuricidade, no sentido de uma inconstitucionalidade de ação estatal (SARLET et al., 2012, p. 338).

Desta forma, defende-se a possibilidade do poder judiciário intervir em situações como esta exemplificada, pois, além de encontrar fundamento(s) na teoria do dever de proteção e na dupla face do princípio da proporcionalidade, especificamente na proibição de proteção insuficiente, poderá ocorrer uma atuação preventiva, de modo que não necessariamente ocorra lesão ao direito fundamental, mas apenas ameaça (de acordo com um fundamento racionalmente justificável), já devendo ser observado o dever de promoção como demonstrado anteriormente:

creditar ao Judiciário a missão de controle e concretização de políticas públicas [...], desde que atue de forma aberta de democrática, conduz ao pensar na promoção de direito de modo préviolatório, abandonando-se a defasada atuação de lógica pósviolatória, que lhe reserva tão somente a missão reparatória e não preventiva (BOLESINA; LEAL, 2013, p. 115).

Neste sentido, com o objetivo de demonstrar a utilização da proibição de proteção insuficiente (Untermassverbot) pelo judiciário, é possível obsevar que a jurisdição constitucional brasileira já vem utilizando tal argumento em algumas de suas decisões. Como exemplo pode-se citar decisão proferida pelo Supremo Tribunal Federal no ano de 2012, no habeas corpus 96.759/CE, que versava sobre porte ilegal de arma. Neste caso, a arma estava sem munição e, portanto, questionava-se se tal fato seria atípico ou não, justamente porque tal situação não possuía entendimento pacífico no presente tribunal.

Em tal caso, decidiu-se que, conforme a Lei 10.826/2003, que, em seu artigo 14 não prevê a necessidade de munição da arma para a caracterização do crime, este entendimento prevaleceu, sendo o porte de arma desmuniciada considerado crime. A proibição de proteção insuficiente (Untermassverbot) foi utilizada nessa decisão não especialmente como fundamento central, mas com papel destacado ao reforçar a ideia defendida no presente estudo de necessária proteção suficiente aos direitos fundamentais, sendo possível a atuação do judiciário. Conforme segue trecho de referida decisão: 
[...] uma vez que se ateste que as medidas legislativas adotadas transbordam os limites impostos pela Constituição - o que poderá ser verificado com base no princípio da proporcionalidade como proibição de excesso (Übermassverbot) e como proibição de proteção deficiente (Untermassverbot) -, deverá o Tribunal exercer um rígido controle sobre a atividade legislativa, declarando a inconstitucionalidade de leis penais transgressoras de princípios constitucionais (BRASIL, 2012, p. 46).

No mesmo sentido, foram encontradas outras duas decisões que versavam sobre o porte ilegal de arma desmuniciada, questionando se seriam tais casos atípicos ou não: o habeas corpus 102.087/MG e o habeas corpus 104.410/RS, ambos avaliados no ano de 2012. Observa-se igualmente nestes dois casos a referência à Lei 10.826/2003 (Estatuto do Desarmamento), que tipifica o porte de arma como crime de perigo abstrato, visto que a lesividade e periculosidade são inerentes a tal objeto. Nestes, pode-se observar que a proibição de proteção insuficiente foi utilizada da mesma forma que no habeas corpus 96.759/CE acima analisado.

No ano de 2006, o mesmo tribunal, ao tratar sobre a ação direta de inconstitucionalidade 1800-1/DF, em 2006, que abordava a questão da gratuidade das primeiras certidões de registro de nascimento e certidão de óbito, refere-se novamente à dupla face do princípio da proporcionalidade, com destaque, neste caso, da necessidade de o Estado proteger a cidadania bem como seu exercício. Pela face de proibição de proteção insuficiente, o princípio da proporcionalidade não estaria violado, decidindo-se pela gratuidade de tais documentos:

\footnotetext{
como se sabe, o princípio da proporcionalidade, bem estudado pela doutrina alemã, corresponde a uma moeda de duas faces: de um lado, tem-se a proibição de excesso (Ubermassverbot) e, de outro, a proibição de proteção insuficiente (Untermassverbot). [...] a medida legal contestada conforma-se perfeitamente à outra faceta do princípio da proporcionalidade acima mencionado, a qual exige que o Estado preste proteção eficaz aos economicamente hipossuficiente, sobretudo no que respeita seus direitos de cidadania (BRASIL, 2007, p. 128-129).
}

Já na ação direta de inconstitucionalidade 3112-1/DF, em 2007, concernente ao requerimento do Partido Trabalhista Brasileiro (PTB) quanto à existência de vício formal de iniciativa do Estatuto do Desarmamento, alegava-se que o Congresso Nacional teria interferido competência privativa do Presidente da República, pois a Constituição Federal (no artigo 61, parágrafo $1^{\circ}$, II, "a" e "e") determina esta competência para a criação, estruturação e atribuições dos Ministérios e órgãos da administração pública. Em resumo, os parágrafos únicos dos artigos 14 e 15, e artigo 21 do Estatuto do Desarmamento foram declarados inconstitucionais. No entanto, não se reconheceu a invasão de competência residual do 
Estado, pois a União pode legislar sobre matérias de interesse predominantemente geral. Também não restou configurada inconstitucionalidade formal, pois os dispositivos impugnados foram tidos como mera reprodução de normas constantes na Lei 9.347/97, que foi de iniciativa do Executivo. Assim, sendo o pedido procedente em parte, nesta decisão a proibição de proteção insuficiente figurou como um dos argumentos apresentados em seu texto, contudo, de forma rasa e menos expressiva.

Não obstante, de forma mais significativa comparece a proibição de proteção insuficiente no recurso extraordinário 418.376-5/MS, também em 2006. Em tal situação, havia ocorrido o crime de estupro de uma criança de nove anos de idade, questionando a hipótese de extinção da punibilidade em razão da convivência entre autor e vítima, visto que, na época, ainda vigorava artigo 107, inciso VII, do Código Penal, que previa a extinção da punibilidade se vítima e autor celebrassem matrimônio. Diante dessas circunstâncias, o Supremo Tribunal Federal apontou a proibição de proteção insuficiente em face de necessidade e do dever de proteger os direitos fundamentais:

A proibição de proteção insuficiente adquire importância na aplicação dos direitos fundamentais de proteção, ou seja, na perspectiva do dever de proteção, que se consubstancia naqueles casos em que o Estado não pode abri mão da proteção do direito penal para garantir a proteção de um direito fundamental (BRASIL, 2006, p. $688)$.

No presente caso, decidiu-se que a criança era absolutamente incapaz e não poderia autodeterminar-se, não sendo configurada a união estável: ademais, "conferir à situação dos presentes autos o status de união estável, equiparável ao casamento, para fins de extinção da punibilidade [...] não seria consentâneo com o princípio da proporcionalidade no que toca à proibição de proteção insuficiente" (BRASIL, 2006, p. 690-691). Além disso, tal decisão reitera o posicionamento de que o princípio da proibição da proteção insuficiente possibilita a atuação do judiciário no controle de políticas públicas na defesa e proteção dos direitos fundamentais "isso porque todos os Poderes do Estado, dentre os quais está evidentemente o Poder Judiciário, estão vinculados e obrigados a proteger a dignidade das pessoas [...]" (BRASIL, 2006, p. 691).

Enfim, diante dos casos estudados, percebe-se que a proibição da proteção insuficiente (Untermassverbot) tem sido utilizado pelo Supremo Tribunal Federal como fundamento e argumento autorizador de sua intervenção na defesa dos direitos fundamentais. Isto se dá a despeito de não ser aproveitado como embasamento principal do mérito das decisões, sendo 
desprezado em relação a outros fundamentos, talvez identicamente relevantes ou menos expressivos no que tange a proteção dos direitos fundamentais como dever constitucional.

\section{RESULTADOS E DISCUSSÕES}

Os resultados da pesquisa efetuada podem ser observados, principalmente, a partir da análise jurisprudencial realizada, a partir da qual se obtiveram seis decisões encontradas no Supremo Tribunal Federal conforme as chaves de pesquisa utilizadas de forma alternada. As decisões encontradas dizem respeito a julgamentos nos anos de 2006, 2007 e 2012, ficando demonstrada a atualidade do tema.

Diante das dinâmicas contemporâneas sociais surgidas, notadamente a partir do Constitucionalismo Contemporâneo, que demandam cada vez mais uma atuação pontual do Estado, o presente trabalho observou que esta atuação não pode se dar de forma aleatória e/ou desconsiderando preceitos mínimos ligados à democracia e à dignidade humana e, assim, apresentou como possível argumento o princípio da proibição da proteção insuficiente para que a atuação do Estado não se dê ignorando estes preceitos.

A concretização e proteção dos direitos fundamentais deve se dar de modo suficiente pelo Estado, de modo a não deixar violado e desprotegido determinado direito fundamental. Logo, quando concretizados por políticas públicas, o mesmo não poderá ocorrer, devendo o Estado prestar iniciativas aptas a tal papel, ficando o poder judiciário no controle do cumprimento deste dever constitucional, justamente na defesa da Constituição. Neste caminho, observando-se a jurisdição constitucional, foi perceptível que o Supremo Tribunal Federal é tímido em relação a este princípio, utilizando-o apenas de modo subsidiário a outros argumentos.

Observa-se que desde o ano de 2006 a proibição de proteção insuficiente (Untesmassverbot) já vem sendo utilizada pela jurisdição constitucional brasileira, não apenas de forma teórica ou retórica, mas também de forma prática. É aplicada na defesa e proteção dos direitos fundamentais, notando-se sua relevante utilização como possibilitador e fundamento da atuação do judiciário na defesa dos direitos fundamentais, apesar de não figurar como argumento central nas decisões de mérito, ficando preterido diante outros argumentos igualmente ou até menos significativos na proteção dos direitos fundamentais. 


\section{REFERÊNCIAS}

BRASIL. Constituição da República Federativa do Brasil (1988). Disponível em: <http : //www.planalto.gov.br/ccivil_03/constituicao/constitui\%C3\%A7ao.htm>. Acesso em: 10 nov. 2013.

BRASIL. Supremo Tribunal Federal. Adin 1800-1/DF. Tribunal Pleno, julgado em 11/06/2007 Min. Rel. Ricardo Lewandowski. Disponível em: <http://www.stj.jus.br>. Acesso em: 10 nov. 2013.

. Supremo Tribunal Federal. Adin 3112-1/DF. Tribunal Pleno, julgado em 02/05/2007 Min. Rel. Ricardo Lewandowski. Disponível em: <http://www.stj.jus.br>. Acesso em: 10 nov. 2013.

. Supremo Tribunal Federal. HC 96.759/CE. Segunda Turma, julgado em 28/02/2012 Min. Rel. Joaquim Barbosa. Disponível em: 〈http://www.stj.jus.br〉. Acesso em: 10 nov. 2013.

Supremo Tribunal Federal. HC 102.087/MG. Segunda Turma, julgado em 28/02/2012 Min. Rel. Celso de Mello. Disponível em: <http://www.stj.jus.br>. Acesso em: 10 mai. 2013.

. Supremo Tribunal Federal. HC 104.410/RS. Segunda Turma, julgado em 06/03/2012 Min. Rel. Gilmar Ferreira Mendes. Disponível em: <http://www.stj.jus.br>. Acesso em: 10 mai. 2013.

- Supremo Tribunal Federal. RE 418.376-5/MS. Segunda Turma, julgado em 09/02/2006 Min. Rel. Gilmar Ferreira Mendes. Disponível em: <http://www.stj.jus.br>. Acesso em: 10 mai. 2013.

BOLESINA, I.; LEAL, M. C. H. O mínimo existencial e o controle jurisdicional de políticas públicas: análise de sua operacionalidade na jurisprudência do Supremo Tribunal Federal e do Superior Tribunal de Justiça. Curitiba: Multideia, 2013.

CARA, J. C. G. de. La dimensión objetiva de los derechos sociales. Barcelona: JMB Bosch, 2010.

CARBONEL, M. El principio de proporcionalidad y la interpretación constitucional. Quito: V\&M Gráficas, 2008.

LEIVAS, P. G. C. Teoria dos direitos fundamentais sociais. Porto Alegre: Livraria do Advogado, 2006.

MARTINS, L. (Org). Cinqüenta Anos de Jurisprudência do Tribunal Constitucional Federal Alemão. Montevideu: Konrad-Adenauer-Stiftung E.V, 2005.

SARLET, I. W.; MARINONI, L. G.; MITIDIERO, D. Curso de Direito Constitucional. Porto Alegre: Revista dos Tribunais, 2012. 
STRECK, L. L. O dever de proteção do estado (schutzpflicht): o lado esquecido dos direitos fundamentais ou "qual a semelhança entre os crimes de furto privilegiado e o tráfico de entorpecentes"?. Disponível em: <http://leniostreck.com.br/index.php?option= com_docman\&Itemid=40>, 11/07/2008. Acesso em: 10 set. 2013.

STRECK, M. L. S. O direito penal e o princípio da proibição de proteção deficiente: a face oculta da proteção dos direitos fundamentais. Dissertação (Mestrado Programa de PósGraduação em Direito) - Universidade do Vale do Rio Sinos, , São Leopoldo, 2008. 